\title{
Evaluating plans of work
}

Article

Accepted Version

Hughes, W. (2001) Evaluating plans of work. Engineering, Construction and Architectural Management, 8 (4). pp. 272283. ISSN 0969-9988 doi: https://doi.org/10.1108/eb021188 Available at https://centaur.reading.ac.uk/4304/

It is advisable to refer to the publisher's version if you intend to cite from the work. See Guidance on citing.

Published version at: http://www.emeraldinsight.com/10.1108/eb021188

To link to this article DOI: http://dx.doi.org/10.1108/eb021188

Publisher: Emerald

All outputs in CentAUR are protected by Intellectual Property Rights law, including copyright law. Copyright and IPR is retained by the creators or other copyright holders. Terms and conditions for use of this material are defined in the End User Agreement.

\section{www.reading.ac.uk/centaur}

\section{CentAUR}

Central Archive at the University of Reading

Reading's research outputs online 


\title{
Evaluating plans of work
}

Will Hughes, Department of Construction Management \& Engineering, University of Reading, PO Box 219, Reading, RG6 6AW, UK

Engineering, Architectural and Construction Management 2001, 8(4), 272-283.

\begin{abstract}
Plans of work for construction projects are published by various interest groups with increasing frequency. Each purports to explain how (all) construction projects should be organized and it can be very difficult to assess their relative benefits and the circumstances most appropriate for their use. Techniques for analysing organizational structures have been available for some decades, but are rarely applied to construction projects. Such techniques can be criticized for omitting non-structural aspects of project management, such as leadership and other behavioural traits but they are ideal for analysing the strengths and weaknesses of documents describing formal organizational structures. A model for evaluating plans of work is presented and, by way of example, a scheme produced by the Construction Industry Board (UK) is analysed by comparison with the RIBA plan of work. The results show that the CIB scheme does not provide proper guidance for the management of projects, neither does it allocate responsibilities to participants. This analysis shows that such techniques are capable of providing useful benchmarks for assessing the differences between plans of work. They enable impartial assessment of the strengths and weaknesses of different schemes.
\end{abstract}

Keywords: benchmarking, Construction Industry Board, organizational analysis, plans of work, project management, RIBA.

\section{Introduction}

Plans of work are schemes that explain how best to organize the processes involved in a construction project. There is an increasing number of such schemes, each seeking to explain how best to organize projects. Although it has been established for many years that there is not one best way to organize per se, (Woodward 1965), there is a tendency for various construction industry institutions to produce schemes that purport to overcome the organizational difficulties associated with running projects. This presents the problem of how to tell whether one plan of work is better than another. There is a tendency for those who publish plans of work to convey the impression (not always explicitly) that their scheme is suitable for all projects. Clearly, this could not be so, since construction projects vary from small domestic refurbishments, to major infrastructure developments. Real construction projects are expensive to experiment with. Thus, there is a need for a technique for evaluating and comparing different plans of work. The purpose of this paper is to present such a technique.

In modelling project organizational structures, Hughes (1989) developed a graphical approach for the purposes of identifying who does what within a project, developing earlier work by (Walker 1980). Such identification of responsibility lends itself to quantitative analysis. Although such analytical approaches to the management of projects might be criticized for failing to take account of informal organizational structures, plans of work are models of a formalized structure and are highly suited to such an approach. Moreover, the quantifications 
that can be derived from such an analysis should enable comparisons between different plans of work and suggestions as to where each might be best suited.

\section{Context of the analysis}

The general framework offered here separates objectives, decisions, control, activity, operations and roles so that each can be separately identified and examined in terms of their structural relationships in any analysis of a particular project (see, for example: Walker and Hughes 1984, 1986, 1987). This framework is the basis for analysing plans of work.

\section{Objectives}

The general view of objectives in construction is that clients want a building on time, within cost limits, to a specific quality (Chartered Institute of Building 1982, Draper 1984, Finn 1984). However, most participants in the construction process focus on their own responsibilities, rather than on the realization of client objectives (Bengtsson 1984, Dawson 1996: 43). This is a result of traditional organization structures of projects and the orientation they impose on the individual. The project objectives are the major determining factor for the objectives for each sub-system. Each sub-system must have its own objectives, orientated to the overall project objective.

\section{Decisions}

In order for a project to progress meaningfully, its objectives, and their achievement, must be closely allied to the decision structure. Decisions give purpose to activity; a project begins and ends with decision points. The trigger decision for a project would be the client's decision to explore the extent to which its objectives can be met by the procurement of a building. Similarly, the completion of the building project is a decision that rests with the client. These two decisions concern matters of client policy, and thus they are termed "Policy Decisions". Although the client's policy will probably vary during the project, this will be a gradual evolution rather than a series of discrete events. Thus, there are only two Policy Decisions for the purposes of this analysis. Between these, other decisions are taken, based upon information generated by the project team, which incrementally commit the client to further expenditure and resources, while offering opportunities to reject work or even abort the project. These decisions, which punctuate stages in the project, are termed "Strategic Decisions".

\section{Control}

The purpose of a Control System is to regulate the work in relation to its (perhaps changing) context. The Control System involves comparing progress to targets and taking some sort of corrective action (Kast and Rosenweig 1985), as shown in Figure 1. The corrective action may take two forms: taking steps to change the performance of the activity to bring it closer to what was planned, or changing the plan so that it more closely reflects the changed situation brought about by the departure from the plan. The Control System requires decisions to be taken at a level more senior than that doing the work. 


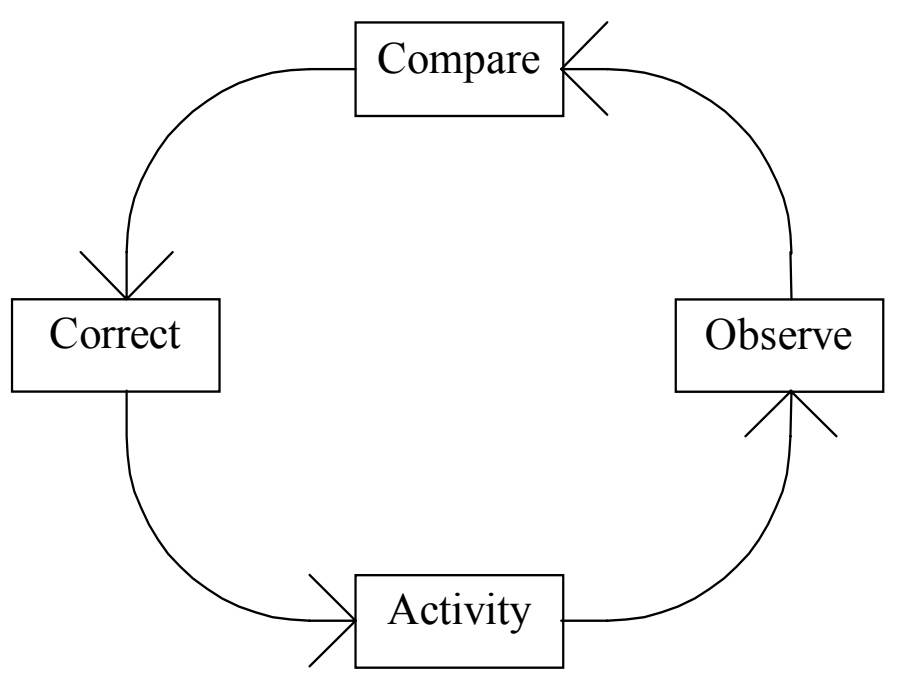

Figure 1: Control System

Control Systems are required for several reasons; cost, quality, time, etc. All plans of work reveal that different types of Control System need to be exerted over a building project (Hughes 1991). A certain amount of control will be needed irrespective of project variables. But the need for control will vary from one project to another, just as project contexts vary. On large and complex projects any of the control aspects could form a separate activity for some person or organizational unit. On smaller jobs it may simply be one aspect amongst many for the project manager or management team.

As Litterer (1973) states,

control is concerned not only with the events directly related to the accomplishment of major purposes, but also with maintaining the organization in a condition in which it can function adequately to achieve these major purposes.

This distinction is important, but not often drawn. Burns \& Stalker (1966) refer to the maintenance of the organization as the Managing System, and Walker (1980) follows this idea. This convention will be followed here. In addition, Control Systems refer to the matching of performances with objectives. The Control System acts as an interface between the Operating System and the Managing System. The Managing System sets the policies and objectives for the project, and the Operating System undertakes work in order to achieve them. The Control System matches activity to objectives in order to ensure that output is orientated towards objectives.

Figure 2 shows how activity, decisions and control are related to each other in the context of project management. The initial decision is termed the "trigger" decision. It is here that the objectives for this particular sub-system are set. The end point is called the "terminal" decision, and this will usually form a trigger for a subsequent subsystem. This pattern occurs in all of the plans of work and is the embodiment of the basic systems model in which the Managing System is triggering, regulating and terminating packages of work. 


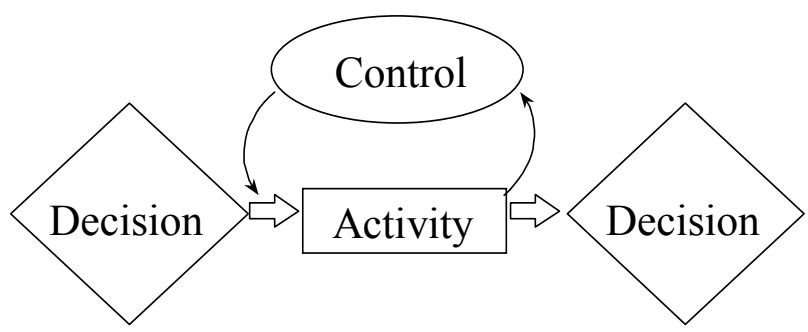

Figure 2: The context of project activity

\section{Activity}

The stages of work identified in published plans of work seek to represent the activities generally found on construction projects. These patterns form the basic frame of reference for what people do in construction projects. Although the separation of work into stages may imply sequential progress, it is rarely intended that stages are absolutely sequential because information may be generated in different ways for different projects. Indeed, it is often the case that stages proceed in parallel. But in strictly organizational terms, stages may begin prematurely on the assumption that a decision will be taken. Such an action is part of the risk taken by consultants and other participants in construction projects. Stages of work are merely generalizations and, as such, much of the detail within a stage may change from one project to another, although not all plans of work convey such flexibility.

Each stage of work can be broken down into Operations that have to be undertaken with a realistic relationship to each other. Further to this, each stage should have its own uniquely identifiable objective. Some activities identified within plans of work, such as briefing and cost control, take place more or less throughout the life of the project. This is because they form part of the Control Process and are in fact components of the management information system for the project.

\section{Operations}

Operations are the components of activity. An Operation is defined as a package of work that can be undertaken by one organizational unit without interruption by decision points (adapted from British Standards Institution 1979). In the "Operating System", Operations may be linked reciprocally or sequentially (Thompson 1967), that is, they may take place in parallel, each feeding information to the other, or they may take place one after the other.

Additionally, within an Operation, different participants may be providing input or receiving output. Thus the work to be done in an Operation consists of combining a variety of information inputs, some from previous or concurrent Operations, and some from participants giving advice and information. These inputs are transformed into information outputs by the exercise of technical skill. The outputs will be made to participants in other Operations, thus forming the inputs of subsequent Operations. Aspects of control may be so significant as to form discrete Operations in their own right on complex projects; but on simple projects they may be reduced to consultation or management functions within Operations.

\section{Hierarchies of decisions}

Decision points form the major boundaries to activities. They can be classed as Policy, Strategic, Tactical and Operational Decisions. The structure of decision points is shown in Figure 3, and their definitions are as follows. 


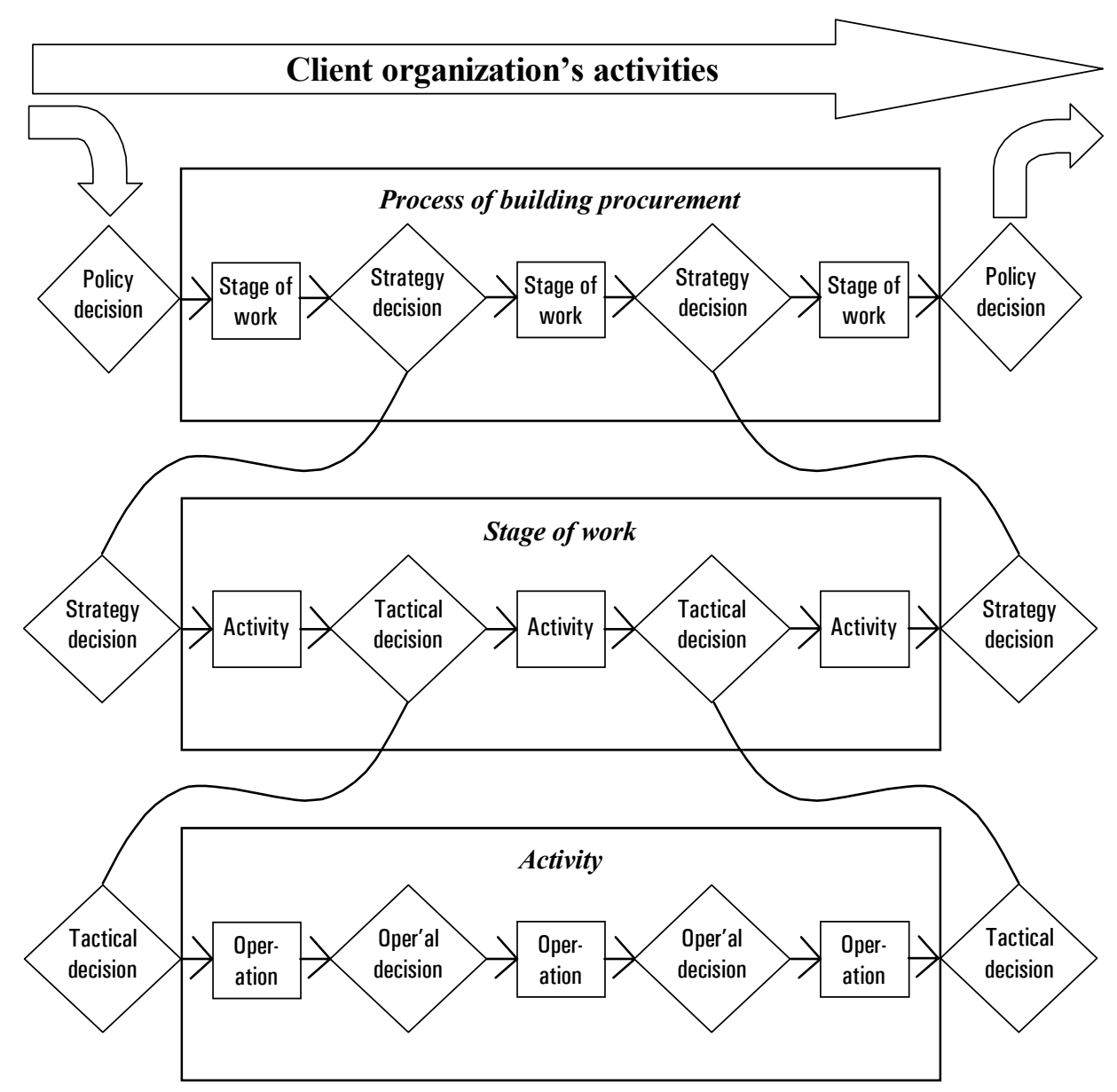

Figure 3: Decisions, stages of work, activities \& operations

- Policy Decisions are the major constraint on any project and determine the framework within which the project takes place. The trigger Policy Decision sets the objectives for the project, and the terminal Policy Decision terminates the project. Premature termination would be a result of major change in the client's policy toward the project. Policy Decisions are the highest-ranking decisions. They define the beginning and end of the "process of building procurement". As such they are at the interface between the macro-environment and the project. In this sense the project exists as a response to the environment, and with the aim of effecting some sort of changes to the environment. This definition results in the Managing System, which regulates, maintains and adjusts the process of building procurement in terms of the project's environment.

- Within the "process of building procurement", Strategic Decisions deal with matters impinging on the project, e.g. the decision to apply for planning permission, or negotiation of terms for site acquisition. Strategy will be mainly concerned with the implementation of client's policy, but will also cover implementation of other policies such as planning approvals. Thus, Strategic Decisions are not always in the hands of the client or even the project team. Strategic Decisions define the beginnings and ends of stages of work. The sub-systems created by Strategic Decisions determine the detailed constraints of the project. Between Strategic Decisions is the Control System, which is concerned with regulating and adjusting the work taking place in terms of the objectives set by the Strategic Decisions. 
Each Strategic Decision results in a new management structure, different from what led to the Decision. Such decisions are not always taken at the Strategy level; they may be delegated. Also, the Decision may not be explicit, in which case, work continues on the assumption (and risk) that it has been taken. However, since the nature of the work alters at these milestones, even if they are not explicit, the work progresses as if they had been.

- Tactical Decisions are concerned with the deployment of resources and the management of the project on a day-to-day basis. They will be within the purview of the project leader, or project manager. Examples of these are the decision to appoint nominated subcontractors for parts of the work, or the decision to adopt certain forms of contract. Tactical Decisions form the boundaries to sub-systems of activity, and constrain the Control Systems.

- Operational Decisions are directly related to Operations as previously defined. By definition, decision points trigger Operations and mark their completion. Therefore, in the absence of a higher rank of decision there will be an Operational Decision. These occur where decentralization of authority is high, and where there is autonomy at the Operational level; thus they may not be explicitly present on many projects. Activity is the term used to describe the groups of Operations between Tactical Decisions. The Operating System is the term used to signify groups of Operations interacting to progress the project incrementally towards the objectives of the stage of work.

Thus, Operations are sub-systems of activity; Activities are sub-systems of stages of work; and stages of work are sub-systems of the process of building procurement. The key point about this analysis is that a participant in the process may be exercising responsibility at any or all of these different levels. It is important to distinguish operational contributions from management contributions. Moreover, it is important to distinguish responsibilities concerned with controlling operational output from responsibilities concerned with maintaining the project organization. Thus, work is separated into Operational, Control and Managing Systems. However, these distinctions are not sufficiently detailed to represent the text of plans of work for the purposes of comparative analysis. Further de-construction of these systems is achieved by considering how roles and patterns of responsibility combine to form the operating, controlling and managing systems.

\section{Roles and responsibilities}

The relationship between a participant and an Operation is known as a role. There is a variety of such roles, and they may be combined for each participant. They will be determined primarily by the purpose of each contribution as well as the participant's skill and ability. Thus, the concept of "role" is given a specific meaning within this type of analysis.

In analysing organizational structures encountered in practice, the degree of detail and the classification of roles are dependent on the depth of the analysis and the purpose of the investigation. Cleland and King (1975) discussed the number and meaning of the roles that might be used in such an analysis and concluded that it depended on the nature and purpose of each analysis, suggesting that this should be an item for 
Table 1: Definitions of roles

\begin{tabular}{ll}
\hline Role & Definition \\
Operating System & \\
Operating & $\begin{array}{l}\text { Carrying out work (i.e. performing an operation) on some aspect of the } \\
\text { project, and having overall responsibility for its output. } \\
\text { Carrying out work as part of a team or committee with partial responsibility } \\
\text { for output. }\end{array}$ \\
Co-operating & $\begin{array}{l}\text { The provision of technical or other information when asked for it. Typically } \\
\text { undertaken in the construction industry by professional consultants. }\end{array}$ \\
Receipt of information about the project for purposes outside the \\
management of the project; for example the accounts department of a client \\
organization.
\end{tabular}

Source: Hughes, 1989

negotiation between the analyst and the organization under scrutiny. This is the only guidance in the literature about how to select the pattern of roles to be used in an analysis. Their purpose was to explain how such an approach is used in describing a real organization, so that the observed structure may be compared to a suggested structure. Since the purpose here is to produce comparative analyses, the set of role codes needs to be consistent.

To derive a consistent set of roles, the three types of system (Operating, Control and Managing ) are further de-constructed as shown in Table 1. This shows how the various combinations of roles provide the organizational systems that are needed for successful management of the processes in design and construction.

Figure 4 portrays the relationships between the roles in the operational, control and managing systems. Recommendations may arise at any level in the hierarchy, and will be subject to Approval by the next level in authority. This Approval may become a Recommendation to someone in a higher managing function again, so the chain of Recommendation and Approval passes up the management hierarchy until it reaches the person who has the ultimate authority for the particular decision being taken. The ultimate authority in the project management system is the client, so the final Approval may end up as a client's Policy Decision. The dynamics of the relationships between roles are shown in Figure 5. 


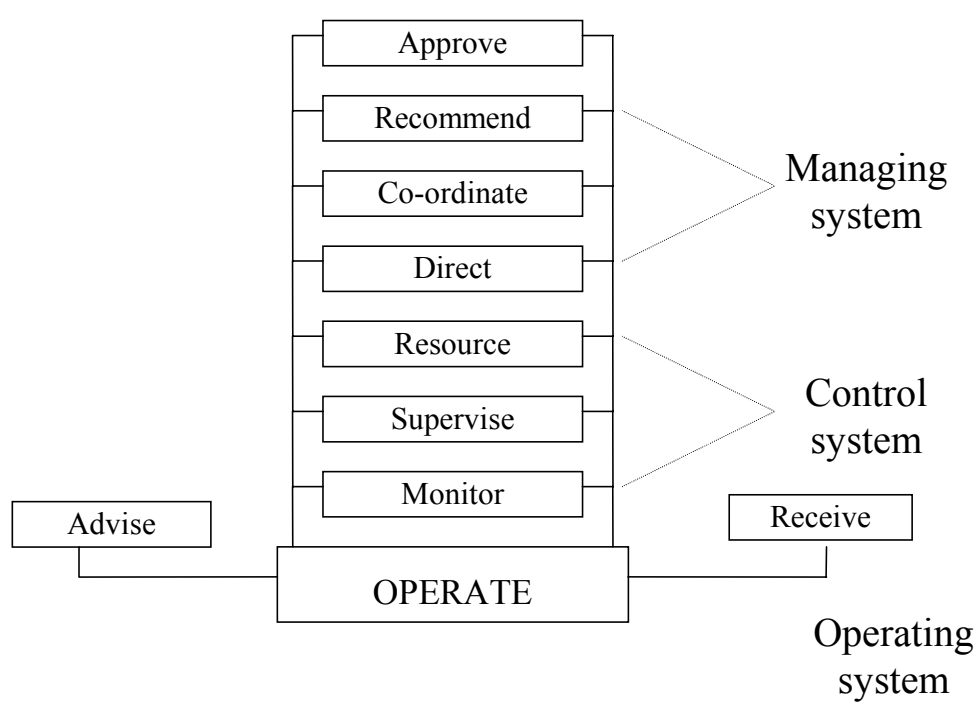

Figure 4: Hierarchy of roles related to systems

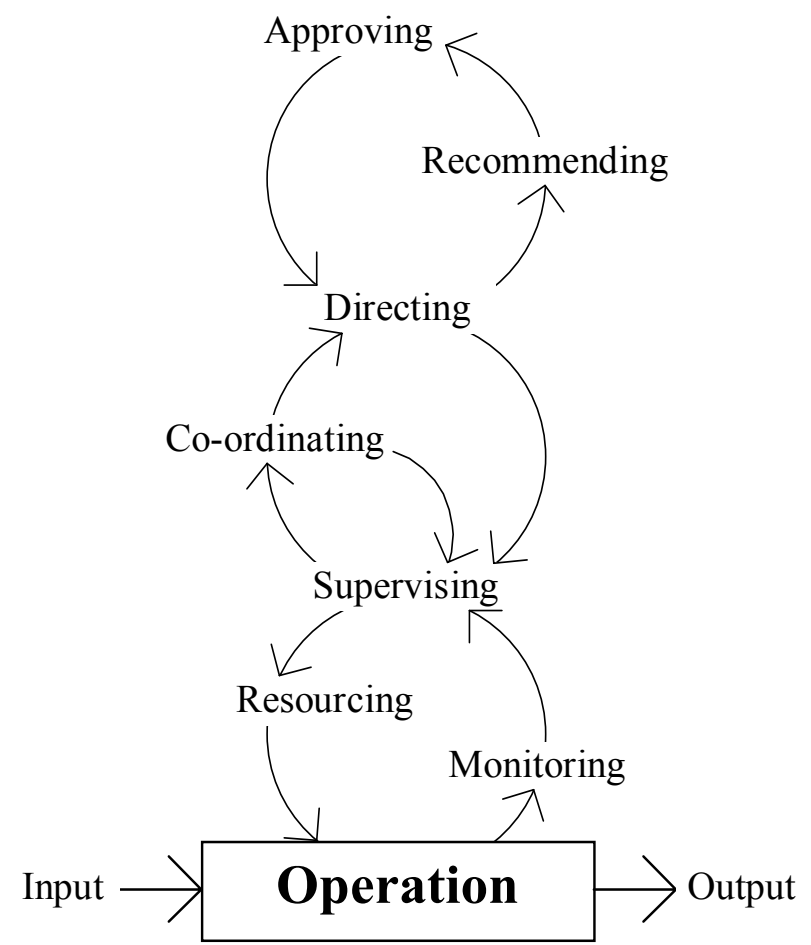

Figure 5: The relationships between roles

Any analysis of a construction project's organization ought to be capable of exposing the situation where integration is achieved through meetings and teamwork. Thus the role of "Co-operating" is defined as membership of a team or committee. This can occur at any level in the system, and has to be identified separately because in such a case, the interaction between those co-operating achieves a certain amount of co-ordination, even in the absence of some specifically exercising that role. In other words, although someone may be appointed to exercise the co-ordinating role, it may take place by virtue of teamwork and meetings (Galbraith 1973).

These role definitions help to define the contribution that each person makes to a project, and they relate to the different type of system. Each of the levels of decision-making constitutes a different level of detail for analysis. In strict systems terms, the Control System described in Figure 1 should be applied at all levels. The practical manifestation of this is the 
communication patterns that are observed at each of the levels. These form the "glue" which binds the different roles at each level and produce the characteristic pattern shown in Figure 2. The process of observation is achieved through the role of Monitoring. This gathering of information must include a certain amount of filtering, to make it effective. Thus the Monitor undertakes some comparison of information to objectives. Information is passed to more senior people in the organization and they also undertake a comparison to the objectives before determining the course of action to take. Control will be achieved by the exercise of supervisory powers, either to change the level of resources available to the Operator, or by changing the plan so that the departure from the plan is removed. This may involve referral to the Managing System for a Strategic Decision. The Control System, then, is achieved through the roles of Monitoring, Supervising and Resourcing.

At Strategic Decision points, the control process becomes the responsibility of a higher level of the hierarchy, and is manifested through the roles of Directing, Recommending and Approving. This is a higher level of control, which involves the client in the decision-making process.

Figure 5 also shows why sometimes decisions from policy makers take a long time to filter down to those who implement them at the Operating System level. Problems may be circulating for a considerable time in the upper portion of the Figure before finally working their way back down to the Operating System. This may be beyond the perception of those on the Operating System who often only perceive the enormous time lag in decision-making, with no appreciation of the structure of the system that produces the decision. It is important to note that, for practical reasons, people at an operational level will frequently predict the decision that will be taken and continue to work assuming that the final decision, when it comes, is merely a confirmation that work is progressing satisfactorily. This may result in abortive work if the decision is not what was expected and is a commercial risk on the part of those at the operational level.

\section{Organizational mapping}

The principles outlined here provide a robust framework of organizational concepts to be used in mapping the formal aspects of various organizational approaches published in the literature. The approach to mapping has been used in various industries in the past, including the construction industry, where, for example, it was used for mapping in great detail the processes observed in four detailed case studies of public sector building projects (Hughes 1989). While the organizational maps produced from such an approach focus on the formal structure, forming the backdrop and context for the interplay between participants in terms of power, leadership, motivation and other important behavioural phenomena, they might be criticized for not identifying informal organizational structures. However, plans of work are themselves a representation of the formal structure of an organization and thus are very conducive to this kind of analysis. The foregoing discussion of organizational structure indicates the nature of the phenomena that will be sought in any evaluation of plans of work.

\section{Organizational matrix}

The approach of this analysis is to reduce a plan of work to a matrix or grid. The first column of each matrix provides a sequential list of the stages of work and activities 


\begin{tabular}{|c|c|c|c|c|c|c|c|c|c|c|c|c|c|c|c|c|}
\hline $\begin{array}{l}\text { Key: } A \text {-Does the work; } B \text {-Co-operates; } C \text { - } \\
\text { Advises; } D \text { - Receives; } E \text {-Monitors; } F \text { - Supervises; } \\
\text { G-Resources; } H \text { - Co-ordinates; I - Directs; } J- \\
\text { Recommends; } K \text {-Approves }\end{array}$ & 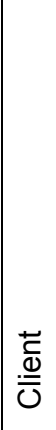 & 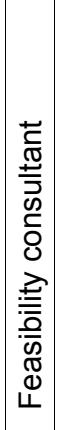 & 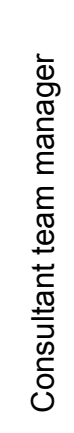 & 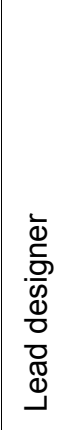 & 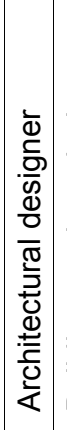 & 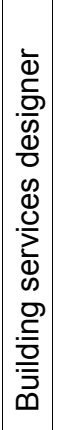 & 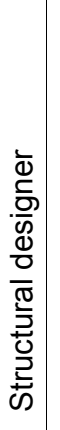 & 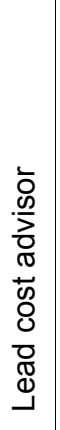 & 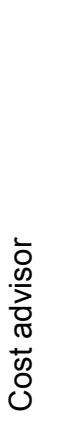 & 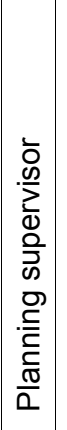 & 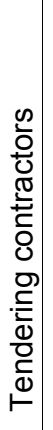 & ְ̃. & 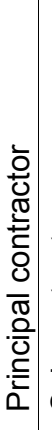 & 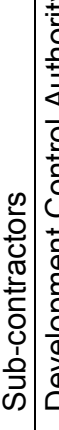 & 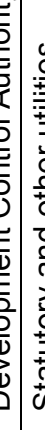 & 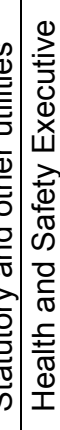 \\
\hline (Decentralization weighting) & 1 & 2 & 2 & 3 & 4 & 4 & 4 & 3 & 4 & 3 & 5 & 5 & 5 & \begin{tabular}{l|l}
67 & 7 \\
6
\end{tabular} & & $\begin{array}{lll}7 & 7\end{array}$ \\
\hline 6. Develop outline proposals & & & $\mathrm{EHI}$ & $\mathrm{AHI}$ & B & $\mathrm{BC}$ & $B$ & & & $\mathrm{C}$ & & & & & & \\
\hline
\end{tabular}

that are identified by the plan of work in question. The remaining columns list every person or organization that is separately identified (either individually or as a member of a group) as contributing in any way to the project. The matrix is then completed by the insertion of code letters to indicate the precise role of a particular person or organization in relation to a particular activity. The codes used for this purpose reflect the definitions of roles explained in the Table 1 of this paper. This reduction of what are often large passages of text to skeleton form (activity/participant/role) produces a common basis for meaningful comparison.

\section{How to read a matrix}

For an example of how to read these matrices, refer to the extract in Table 2. This shows that the Lead Designer is responsible for doing this work (Operating) and for Co-ordinating other inputs to this task as well as Directing the work. It also shows the Consultant Team Manager with responsibility for Monitoring, Co-ordinating and Directing. (This overlap arises because the particular source document in this case defines the responsibility twice, for different participants.) Further along the row, a series of Bs shows that the Architectural Designer, the Building Services Designer and the Structural Designer are Co-operating, meaning that they are providing output that contributes to the outline proposals. Finally, the Building Services Designer and the Planning Supervisor are providing advice. In summary, this particular row shows that there is some confusion over who is co-ordinating the output of the various designers and that the Services Designer is advising on one aspect of the design while contributing output related to the design. No one is allocated explicit responsibility for Supervising (i.e. choosing what corrective action should be taken in the event that the work departs from what was planned) or for Resourcing (i.e. ensuring that those who are undertaking the work have the resources to do it). The fact that no one is making recommendations at this point is not a problem, since recommendations would arise towards the end of a stage of work for client approval.

This example shows how each row of a chart describes in some detail what work has to be done, the information and reporting system as well as the management of the work. By looking at the changing patterns of management roles from one task to another, discontinuities can be identified. By examining the contents of a column of a chart, the precise obligations of each participant can be elicited, including the way that his or her involvement changes during the project.

\section{Analysis}

In order to examine the matrices for any systematic differences, a few measures can usefully be calculated. These are not intended to constitute a comprehensive analysis of an 
organizational structure, but to serve as an indication of the kinds of things that can be analysed from such matrices and of the comparisons that might be made between plans of work in future applications of this method.

- Operations: The number of operations indicates the scale of a project, in the perception of those who drafted the documentation. Each line of an organizational matrix contains one operation.

- Complexity: A good indicator of organizational complexity is the number of people involved in each operation. The simplest operations can be accomplished by one person undertaking operational work, without being managed by others. Clearly, more complex tasks require larger numbers of skills divided between different people operating in diverse capacities. A simple count of complexity can be derived by counting the number of role codes entered into each row of the matrix. For example, the operation shown in Table 2 has a complexity of 11 , since there are 11 roles assigned to participants. This measure is broadly compatible with the few previous attempts at measuring complexity (Gidado 1996, Doyle and Hughes 2000).

- Load: Role codes can be combined within individuals, and the extent to which individual job titles are called upon to undertake multiple roles is referred to as the "load". This can be calculated as an average for each stage of work, and for the project as a whole. A load of 1.0 indicates that each participant has only one role code in the matrix. Larger numbers indicate that participants are being called upon to act in a variety of capacities. For example, in stage B of the JCT draft schedule, the load averages to 1.0 , because each person is involved in only one capacity.

- Decentralization: The involvement of people other than the client comes about not only because the client engages staff, consultants and contractors, but also because of the involvement of external agencies (e.g. planning authority). Some participants are closer than others to the client. A weighting has been applied subjectively, but consistently, to the various role occupants on the basis that the consultants are closer than contractors, who are, in turn, closer to the client than sub-contractors. Statutorily defined roles, such as Planning Officer, are furthest from the client. These weightings enable an indication of the level of decentralization to be calculated, simply by multiplying the number of role codes $(r)$ for a participant by the weighting $(w)$, and dividing by the number of role codes in the row $(n)$. This can be expressed as:

$$
\frac{\sum r \times w}{n}
$$

Higher values indicate higher levels of decentralization. To calculate the extent of decentralization for a stage of work, the values for all the operations within a stage can be averaged.

- Interfaces: One very important aspect of organizing project work is the number of interfaces between participants. This can be difficult to quantify, as there are many ways in which people interact. For the purposes of analysis, the method involves counting the number of participants acting in an operational capacity (role codes " $\mathrm{A}$ " or "B") and finding the number of links between them. To these the numbers of consultations have to be added, calculated by multiplying the number of participants with role code "A" by those with role code "C".

- Control: Control is exercised when work is monitored, supervised and resourced. According to the framework presented earlier in this paper, this combination of roles 
ought to be present in each operation. Therefore, assessing the amount of control is simply a matter of counting how many of these three roles are present in each operation, and representing this as a percentage.

- Co-ordination: Co-ordination is the corollary of skill diversity. To provide a simple measure, the matrices can be examined to count the number of operations in which the role code " $\mathrm{H}$ " is present. This is a simplification because work may be co-ordinated because of the use of standards or procedures, because of familiarity of the participants with each other's ways of working and other reasons. However, for the purposes of comparing plans of work, the key variable is the presence or absence of co-ordination as a role specifically allocated to someone in a management capacity. This can be presented as the number of operations including someone in role code " $\mathrm{H}$ ", expressed as a percentage of all the operations in a stage or project.

To illustrate the application of these ideas, a relatively straightforward scheme has been chosen. Constructing Success emerged as a response to Latham (1994). It provides guidance on how to organize the construction process (Construction Industry Board 1997a). Although the complementary document, Selecting consultants for the team (Construction Industry Board 1997b) appears to have been produced to be used alongside Constructing success, certain activities appear in a different sequence there. For example, the client's advisor is appointed after the strategic brief is developed, rather than at the beginning. Similarly, the client is urged to appoint a tender board "at the outset" in the Selecting Consultants document. The approach to project organization that is represented by these documents is portrayed as a matrix in Table 3.

\section{General comments on CIB Scheme}

The documents contain little detail about who does what and, as such, do not provide adequate guidance on how to manage a project. The two source documents contain many definitions, but each has its own glossary and some of the entries giving contradictory definitions. There is some useful guidance on management of the design process, with clear identification of responsibility for Directing and for Approving work. In fact, the client is involved at every point in the scheme. The client project manager is responsible for most of the project management functions, but there is very little evidence of the need for Coordination in the documentation. 


\section{Example of application: Construction Industry Board}

Table 3: Example of a matrix - Construction Industry Board

\begin{tabular}{|c|c|c|c|c|c|c|c|c|c|c|c|c|c|c|c|c|}
\hline $\begin{array}{l}\text { Key: } A-\text { - Does the work; } B \text {-Co-operates; } C- \\
\text { Advises; } D \text { - Receives; } E \text {-Monitors; } F-\text { - Supervises; } \\
\text { G - Resources; H-Co-ordinates; I - Directs; J- } \\
\text { Recommends; } K \text { - Approves }\end{array}$ & $\frac{\overrightarrow{\bar{\sigma}}}{\overline{\underline{\omega}}}$ & 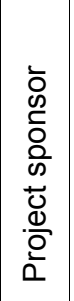 & 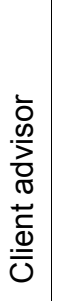 & 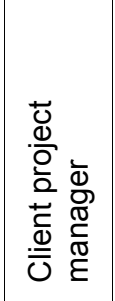 & 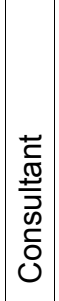 & 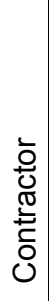 & \begin{tabular}{|l|}
$\bar{\Phi}$ \\
$\bar{\Xi}$ \\
. $\bar{D}$ \\
$\Phi$ \\
$\Delta$ \\
\end{tabular} & 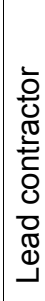 & 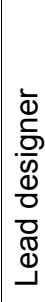 & 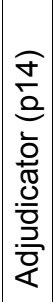 & 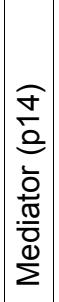 & & 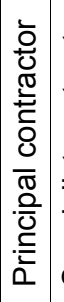 & 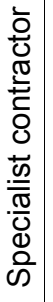 & 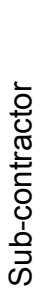 & 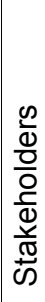 \\
\hline Decentralization weighting & 1 & 2 & 2 & 2 & 3 & 5 & 4 & 5 & 3 & 3 & 3 & 3 & 5 & 6 & 6 & 7 \\
\hline $\begin{array}{l}\text { Getting started } \\
\text { Nominate and appoint the project sponsor }\end{array}$ & A & C & & & & & & & & & & & & & & \\
\hline Appoint client advisor & A & & C & & & & & & & & & & & & & \\
\hline Appraise options & $\mathrm{K}$ & AlJ & B & & & & & & & & & & & & & \\
\hline Confirm the business case & $\mathrm{K}$ & AlJ & B & & & & & & & & & & & & & \\
\hline Develop a project strategy & & A & B & & & & & & & & & & & & & \\
\hline $\begin{array}{l}\text { Decision: Confirm construction project needed } \\
\text { and agree strategy for execution }\end{array}$ & $\mathrm{K}$ & $\mathrm{J}$ & & & & & & & & & & & & & & \\
\hline Select and appoint client's project manager & $\mathrm{K}$ & AlJ & B & C & & & & & & & & & & & & \\
\hline $\begin{array}{l}\text { Defining the project } \\
\text { Develop strategic brief }\end{array}$ & $\mathrm{K}$ & HJK & & AEFGJ & & & & & & & & & & & & C \\
\hline Develop project execution plan & $\mathrm{K}$ & JK & & AEFGJ & & & & & & & & & & & & \\
\hline $\begin{array}{l}\text { Assembling the team } \\
\text { Decide contracts }\end{array}$ & & $\mathrm{K}$ & & AEFGJ & & & & & & & & & & & & \\
\hline Select the project team & & $\mathrm{K}$ & & AEFGJ & & & & & & & & & & & & \\
\hline Appoint the project team & A & & & EFG & & & & & & & & & & & & \\
\hline $\begin{array}{l}\text { Designing and constructing } \\
\text { Develop the project brief }\end{array}$ & BIK & $\mathrm{HI}$ & & AEFG & B & B & B & B & B & & & B & B & B & B & C \\
\hline Develop the concept design & IK & & & EFGG & & & & & & & & & & & & \\
\hline Develop the detailed design & IK & CJ & & EFGH & & C & & & & & & & & C & C & \\
\hline Start construction & 1 & & & EFG & & A? & & & & & & & & & & \\
\hline Payments to contractor & A & & & EFG & & & & & & & & & & & & \\
\hline Manage and resolve problems & 1 & & & EFG & & & & & & A & A & & & & & \\
\hline Review progress and quality & 1 & $\mathrm{~K}$ & & EFGJ & & & & A & & & & & & & & \\
\hline $\begin{array}{l}\text { Completion and evaluation } \\
\text { Ensure work is ready for use }\end{array}$ & & & & EFG & & & & & & & & & & & & \\
\hline Complete the project & $\mathrm{K}$ & $\mathrm{HJ}$ & & EFGJK & & & & A & & & & & & B & B & \\
\hline Evaluate feedback & B & A & & BEFG & & & & & & & & & & & & C \\
\hline
\end{tabular}

The definition of "consultant" encompasses the definition of designer, so both seem to apply to those with design responsibility. However, the distinction between consultant and designer seems not to be followed in the source documentation.

\section{Comparison of CIB scheme with RIBA plan of work}

The results of the analysis of the CIB scheme are given in Table 4, and Table 5 shows the results of an analysis of the RIBA plan of work (Royal Institution of British Architects 1991, 1997), for the purposes of comparison (one of the best known such plans). One interesting comparison is that the amount of detail in the RIBA plan produces a matrix of some 200 lines, 
or about 6 pages of A4 paper (too large to show here), significantly larger than the CIB scheme.

The CIB scheme has only five stages and 22 operations, far fewer than the 11 stages and 184 operations of the RIBA plan, indicating that the CIB approach to planning a construction project seems to be far less detailed than that of the RIBA.

The CIB score for complexity, of 138 in total, is, again, far lower than the 1032 scored by the RIBA plan. This indicates an enormous difference in the expectations of those who drafted these two plans, more than simply a difference of emphasis.

The load for the CIB scheme averages out to 2, which is a higher number than would be expected because it indicates that, on average, people are undertaking 2 different roles throughout the period of their involvement. This high average is caused by the multiple roles demanded of the Client Project Manager throughout the project, but particularly during stages 2 and 3, where the Client Project Manager is undertaking most of the roles, with very little participation from anyone else. By comparison, the overall average load in the RIBA plan is 1.4 , varying from 1.1 to 1.6 , indicating a somewhat more consistent picture throughout a project.

Decentralization for the CIB scheme produces a score that indicates delegation of the client's authority to key people in the team, without this being passed too far down the line. However, like the score for load, there are large fluctuations as the project passes from one stage to another. In this case, the decentralization tends to be much higher during the later stages of the project, indicating a progressively increasing level of delegation of authority as the project develop. For the RIBA plan, decentralization is higher throughout the project and also shows a gradual increase as the project progresses.

There are very few interfaces in the CIB scheme, with some stages containing no interfaces between participants at all. Nearly all of the interfaces between participants occur during stage 4, which covers all of the design and construction work for the project. The overall total of 83 interfaces in the project is dwarfed by Stage C (outline proposals) alone in the RIBA plan, which produces an overall total of 740, again indicating vastly more interaction between participants than envisaged by CIB.

Control scores very high indeed in the CIB scheme, running at $100 \%$ for all but the first stage. By contract, the RIBA plan shows almost no control, other than during the construction stage $(\mathrm{K})$.

Co-ordination is patchy and erratic in the CIB scheme, reflecting the occasional mentions of such roles within the source documentation. In the RIBA scheme, it is practically nonexistent.

\section{Discussion}

The numerical analysis of the matrices produces useful indicators for comparison. There are clearly great differences in the scope of the two plans considered here, although neither of them purports to be directed at particular kinds of project, even though that would provide good reasons for these differences. Clearly, the CIB scheme is not intended to convey the amount of detail found in the RIBA plan. The scores for complexity, load, decentralization and interfaces all confirm that huge differences between the two scheme, as well as highlighting interesting 


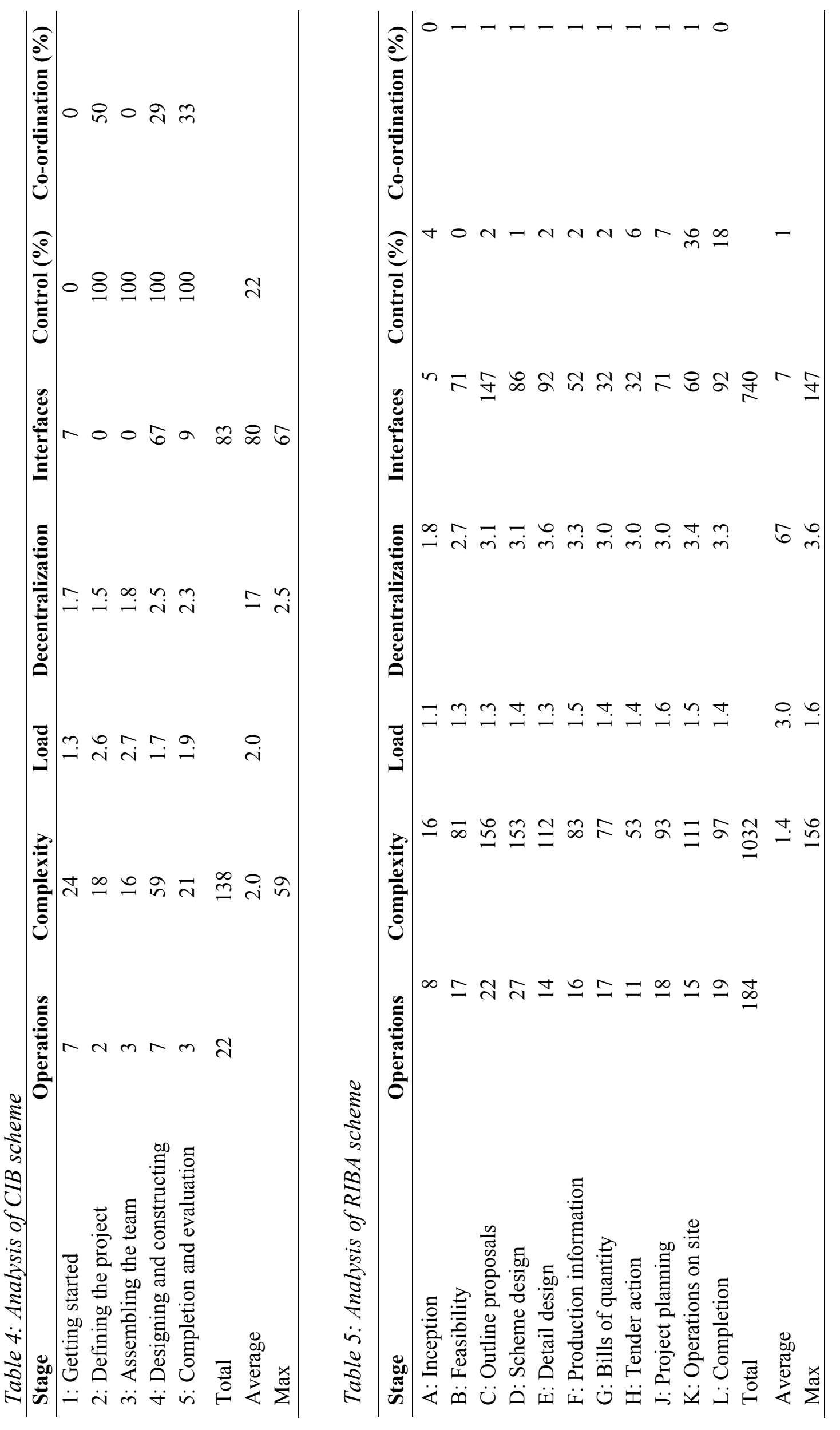



inconsistencies within each scheme. The contrast with the measure for control is stark. This may have come about because the RIBA plan was originally drafted when control and management was not usually imposed on to the work of professionals, who were usually responsible for ensuring that their output was suited to its purpose. The prevailing attitude these days is that it is just as appropriate to apply management to the work of professionals as it has always been to the work of operatives. In a similar way, co-ordination is more apparent in the CIB scheme than it is in the RIBA plan. Of course, none of these schemes of plans of work tell the whole story and while each of the approaches analysed here are drawn from two separate source documents, the shortcomings of those documents will be completed by further professional service contracts, schedules of services, specifications and common working practices.

\section{Conclusion}

The technique described in this paper provides a robust and impartial basis for analysing the contents of plans of work. The proposals of the Construction Industry Board, analysed to illustrate the way that the technique is applied, provide for a project with few clearly defined activities and few specific responsibilities. By comparison, the RIBA plan of work, which has been in existence for nearly 40 years, goes to nearly ten times as much detail in terms of identifying the operational work and the interactions between participants, but fails to touch upon important issues of management. In the CIB scheme, much of the management required for the project resides with the client project manager, in conjunction with the project sponsor. Very few other roles are clearly articulated and there is no detail about the responsibilities for designing and constructing a project. The analysis reveals that the source documentation for the CIB scheme provides little guidance about what work has to be done, by whom, and how each participant interacts with others.

This analytical approach provides a method whereby plans of work can be compared to each other, and the quantitative results provide a technique for benchmarking such schemes.

Moreover, this approach lends itself to a variety of quantitative tests for assessing the extent to which published plans of work meet the expectations of those at whom they are targeted.

\section{Acknowledgements}

I would like to thank the Joint Contracts Tribunal for their sponsorship and careful management of the research project of which the work reported here forms a part. Thanks are also due to Professor John Murdoch for his invaluable assistance with this work and to the anonymous referees for their useful comments on the first draft of this paper.

\section{References}

Bengtsson, S. (1984) Conformity between project objectives and company goals. In), Procs CIB W-65 4th Int Symp on Organization and Management of Construction. Waterloo, Canada, July 1984. CIB,

British Standards Institution (1979) BS 3138: Glossary of terms used in management services. 1992, London: British Standards Institution.

Burns, T. and Stalker, G. M. (1966) The management of innovation. London: Tavistock.

Chartered Institute of Building (1982) Project management in building. Ascot: The Chartered Institute of Building.

Cleland, D. I. and King, W. R. (1975) Systems Analysis and Project Management. New York: McGraw-Hill. 
Construction Industry Board (1997a) Constructing success: code of practice for clients of the construction industry. London: Thomas Telford.

Construction Industry Board (1997b) Selecting consultants for the team. London: Thomas Telford.

Dawson, S. (1996) Analysing organizations. 3ed. Basingstoke: Macmillan.

Doyle, A. and Hughes, W. P. (2000) The influence of project complexity on estimating accuracy. In: Akintoye, A. (Ed.), 16th Annual ARCOM Conference. Glasgow Caledonian University, 6-8 September 2000. Association of Researchers in Construction Management, 623-634.

Draper, K. (1984) Systematic quality appraisal In: Brandon, P. and Powell, J. (Eds) Quality and profit in building design London: Spon.

Finn, M. D. (1984) Project management in development: a checklist. London.: Henry Stewart Publications.

Galbraith, J. (1973) Designing complex organizations. Massachusetts: Addison-Wesley.

Gidado, K. I. (1996) Project complexity: the focal point of construction planning. Construction Management and Economics, 14(3), 213-225.

Hughes, W. P. (1989) Organizational analysis of building projects. Unpublished PhD Thesis, Department of Surveying, Liverpool Polytechnic.

Hughes, W. P. (1991) Modelling the construction projects using plans of work. In: Horner, R. M. W. (Ed.), 4th Yugoslav Symposium on Organization and Management in Construction. Dubrovnik, 81-86.

Kast, F. E. and Rosenweig, J. F. (1985) Organization and management: a systems and contingency approach. Maidenhead: McGraw-Hill.

Latham, M. (1994) Constructing the team: final report of the government/industry review of procurement and contractual arrangements in the UK construction industry. London: HMSO.

Litterer, J. A. (1973) The analysis of organizations. 2ed. New York: Wiley.

Royal Institution of British Architects (1991) Architect's Handbook of Practice Management. London: RIBA Publications Ltd.

Royal Institution of British Architects (1997) Plan of work for design team operation. London: RIBA Publications Ltd.

Thompson, R. D. (1967) Organizations in action. New York: McGraw-Hill.

Walker, A. (1980) A model for the design of project management structures for building clients. Unpublished PhD Thesis, Department of Surveying, Liverpool Polytechnic.

Walker, A. and Hughes, W. P. (1984) Private industrial project management: a systems-based case study. Construction Management and Economics, 2(2), 93-110.

Walker, A. and Hughes, W. P. (1986) A conventionally-managed project: A systems-based case study. Construction Management and Economics, 4(1), 47-74.

Walker, A. and Hughes, W. P. (1987) A project managed by a multi-disciplinary practice: a systemsbased case study. Construction Management and Economics, 5(2), 123-140.

Woodward, J. (1965) Industrial organization: theory and practice. London: Oxford University Press. 